\title{
Plasmodium falciparum artemisinin resistance monitoring in Sabah, Malaysia: in vivo therapeutic efficacy and kelch13 molecular marker surveillance
}

\author{
Matthew J. Grigg 1,2* (D, Timothy William 2,3,4 , Kim A. Piera ${ }^{1,2}$, Giri S. Rajahram²,4,6, Jenarun Jelip ${ }^{7}$, Ammar Aziz ${ }^{1}$, \\ Jayaram Menon ${ }^{4,6}$, Jutta Marfurt ${ }^{1}$, Ric N. Price ${ }^{1,8}$, Sarah Auburn ${ }^{1}$, Bridget E. Barber ${ }^{1,2,5}$, Tsin W. Yeo ${ }^{1,2,9,10 \dagger}$ \\ and Nicholas M. Anstey ${ }^{1,2+}$
}

\begin{abstract}
Background: Spreading Plasmodium falciparum artemisinin drug resistance threatens global malaria public health gains. Limited data exist to define the extent of P. falciparum artemisinin resistance southeast of the Greater Mekong region in Malaysia.

Methods: A clinical efficacy study of oral artesunate (total target dose $12 \mathrm{mg} / \mathrm{kg}$ ) daily for 3 days was conducted in patients with uncomplicated falciparum malaria and a parasite count $<100,000 / \mu \mathrm{L}$ admitted to 3 adjacent district hospitals in Sabah, East Malaysia. On day 3 and 4 all patients were administered split dose mefloquine (total dose $25 \mathrm{mg}$ / $\mathrm{kg}$ ) and followed for 28 days. Twenty-one kelch 13 polymorphisms associated with P. falciparum artemisinin resistance were also evaluated in P. falciparum isolates collected from patients presenting to health facilities predominantly within the tertiary referral area of western Sabah between 2012 and 2016.
\end{abstract}

Results: In total, 49 patients were enrolled and treated with oral artesunate. 90\% (44/49) of patients had cleared their parasitaemia by $48 \mathrm{~h}$ and 100\% (49/49) within $72 \mathrm{~h}$. The geometric mean parasite count at presentation was 9463/ $\mu \mathrm{L}(95 \% \mathrm{Cl} 6757-13,254)$, with a median time to $50 \%$ parasite clearance of $4.3 \mathrm{~h}$ (IQR 2.0-8.4). There were $3 / 45$ (7\%) patients with a parasite clearance slope half-life of $\geq 5 \mathrm{~h}$. All $278 \mathrm{P}$. falciparum isolates evaluated were wild-type for kelch13 markers.

Conclusion: There is no suspected or confirmed evidence of endemic artemisinin-resistant $P$. falciparum in this pre-elimination setting in Sabah, Malaysia. Current guidelines recommending first-line treatment with ACT remain appropriate for uncomplicated malaria in Sabah, Malaysia. Ongoing surveillance is needed southeast of the Greater Mekong sub-region.

Keywords: Plasmodium falciparum, Malaria, kelch, K13, Artemisinin-resistance

\section{Background}

The spread of Plasmodium falciparum artemisinin resistance from Southeast Asia threatens global malaria

\footnotetext{
*Correspondence: matthew.grigg@menzies.edu.au

${ }^{\dagger}$ Tsin W. Yeo and Nicholas M. Anstey contributed equally to this work ${ }^{2}$ Infectious Diseases Society Sabah-Menzies School of Health Research Clinical Research Unit, Kota Kinabalu, Sabah, Malaysia

Full list of author information is available at the end of the article
}

elimination efforts $[1,2]$. To date public health concerns have focused on the significant danger of artemisininresistant $P$. falciparum spreading westwards from Greater Mekong region into the Indian subcontinent and onwards to sub-Saharan Africa, where the majority of the global burden of disease exists [3, 4]. However, monitoring for the south-eastward spread of artemisinin resistance to other endemic countries in Southeast Asia, many of which are approaching elimination of $P$. falciparum 
and other human-only Plasmodium species, is also essential to ensure that the significant public health gains in this region are not lost [3].

The discovery of molecular markers associated with $P$. falciparum artemisinin resistance on the kelch gene on chromosome 13 (kelch13) [5] has provided an important tool for effective molecular surveillance $[1,2,6]$, which can help define the geographical spread of resistant parasites, and guide targeted malaria public health activities. Early detection of $P$. falciparum artemisinin resistance also facilitates optimal treatment strategies to protect the concurrent development of resistance in longer-acting artemisinin-based combination therapy (ACT) partner drugs, such as piperaquine [7-9].

In Malaysia, the reported number of falciparum malaria cases has decreased from around 5000 in 2010 to less than 20 in 2017; with progress on track to meet the national WHO elimination goal for human-only malaria by 2020 [3]. Malaysia borders Thailand where artemisinin-resistant $P$. falciparum is established. At the time of study design, no previous studies had evaluated the presence of artemisinin resistance in Malaysia, particularly in East Malaysia on the island of Borneo where the majority of $P$. falciparum transmission occurs $[10,11]$. To determine whether artemisinin-resistant $P$. falciparum was present in Sabah, Eastern Malaysia, a clinical efficacy study of oral artesunate was conducted with complementary parasite molecular studies to genotype kelch13 polymorphisms associated with artemisinin resistance.

\section{Methods}

\section{Clinical efficacy study}

Patients were enrolled from October 2012 to February 2016 at 3 adjacent district hospital sites at Kudat, Kota Marudu and Pitas in northwest Sabah, Malaysia. Patients weighing more than $10 \mathrm{~kg}$ and up to 65 years of age were enrolled if they had acute uncomplicated malaria, confirmed by positive blood smear for asexual forms of $P$. falciparum on hospital microscopy, with a parasite count between 1000 and $100,000 / \mu \mathrm{L}$, a positive $P$. falciparum histidine-rich protein 2 (Pf-HRP2) result on malaria rapid diagnostic test (CareStart ${ }^{\mathrm{TM}} \mathrm{Pf} / \mathrm{Pan}$, Access Bio, USA), a documented temperature $>37.5^{\circ} \mathrm{C}$ or a history of fever in the last $48 \mathrm{~h}$. Written informed consent was obtained in all patients, including from a relevant parent/guardian for those $<18$ years of age. Patients were excluded if there were any WHO-defined clinical or laboratory signs of severe malaria [12], or they had a haemoglobin concentration at presentation $<7 \mathrm{~g} / \mathrm{dL}$, had received artemisinin-containing therapy in the previous 7 days, had a concurrent acute illness was present, had a previous splenectomy, or, for females, if they were pregnant or breastfeeding. Subsequent diagnostic PCR was conducted for all microscopy positive patients [13, 14]; only those with $P$. falciparum confirmed infections were included in the final analysis.

Patients received oral artesunate alone daily for 3 days [target dose $4 \mathrm{mg} / \mathrm{kg}$, using $75 \mathrm{mg} / 5 \mathrm{~kg}$ dose-weight banding increments (Table 1)] [1], followed by oral mefloquine (target dose $25 \mathrm{mg} / \mathrm{kg}$, split in 2 doses of $15 \mathrm{mg} /$ $\mathrm{kg}$ and $10 \mathrm{mg} / \mathrm{kg}$ ) over 2 subsequent days (Artequin ${ }^{\circledR}$, Novartis, Switzerland). Demographic, clinical and laboratory data were collected at presentation and then daily during hospital admission. Blood slides for microscopy were obtained 6-hourly until a minimum of 2 consecutive negative results were recorded. Whole blood samples were collected at enrolment, then at 24,48 , and $72 \mathrm{~h}$ after treatment, and at final follow-up 28 days after enrolment.

\section{kelch13 molecular surveillance}

Molecular markers previously associated with $P$. falciparum artemisinin resistance were evaluated using PCR to detect 21 single nucleotide polymorphisms on the kelch13 gene (see Additional file 1), as previously described [5, 15]. Additional patients evaluated for kelch13 mutations included those with falciparum malaria excluded from the clinical trial, but who were enrolled in a concurrent clinical malaria study at the same sites and during the same study period [16], as well as patients with falciparum malaria enrolled in an ongoing prospective malaria study at the state tertiary referral hospital in Kota Kinabalu from 2010 to 2016 [17].

Data were entered into Epidata (version 3.1) and analysed using Stata (version 12). Microscopic asexual parasitaemia and gametocytaemia were calculated from thick blood smears [18]. Best-fit linear or tobit regression models were used to estimate the curve of $\log _{\mathrm{e}}$ parasite counts over time [19].

\section{Results}

\section{Clinical efficacy study}

852 patients with malaria were admitted to the study site hospitals, of whom 59 patients with $P$. falciparum on screening microscopy were enrolled into the study (Fig. 1). Of these patients, 49 with P. falciparum infection met the study inclusion and exclusion criteria and were included in the final analysis (Table 2). The median age was 18 (IQR 11-31), with 14 (29\%) children aged 12 years or less. There were 7 (14\%) patients with a previous selfreported history of malaria requiring hospital admission, and the median duration of preceding fever was 5 days. The most common presenting symptom was headache (92\%), followed by chills or rigors (67\%), vomiting (49\%), and muscle and joint pain (45\%). At presentation, the geometric mean parasite count was $9463 / \mu \mathrm{L}(95 \%$ CI 6757-13,254), and 24 (49\%) patients had anaemia (using 
Table 1 Oral artesunate dose-bodyweight banding

\begin{tabular}{lllll}
\hline $\begin{array}{l}\text { Dose } \\
\text { band }\end{array}$ & $\begin{array}{l}\text { Bodyweight } \\
(\mathbf{k g})\end{array}$ & $\begin{array}{l}\text { Total dose } \\
(\mathbf{m g})\end{array}$ & $\begin{array}{l}\text { Number } \\
\text { of patients }\end{array}$ & $\begin{array}{l}\text { Dose (mg)/ } \\
\text { bodyweight (kg) } \\
\text { (mean, SD) }\end{array}$ \\
\hline 1 & $10-16$ & 150 & 4 & $11.1(2.6)$ \\
2 & $17-22$ & 225 & 5 & $11.6(1.0)$ \\
3 & $23-28$ & 300 & 3 & $11.8(1.1)$ \\
4 & $29-34$ & 375 & 5 & $11.9(0.8)$ \\
5 & $35-41$ & 450 & 5 & $12.0(0.6)$ \\
6 & $42-47$ & 525 & 4 & $11.5(0.3)$ \\
7 & $48-53$ & 600 & 11 & $11.9(0.5)$ \\
8 & $54-59$ & 675 & 6 & $12.2(0.3)$ \\
9 & $60-65$ & 750 & 4 & $12.0(0.4)$ \\
10 & $66-72$ & 825 & 1 & $11.4(-)$ \\
11 & $73-77$ & 900 & 0 & - \\
12 & $78-85$ & 975 & 1 & $11.9(-)$ \\
\hline
\end{tabular}

WHO age-related criteria [20]), $3(6 \%)$ patients had acute kidney injury (KDIGO criteria [21]) and a single patient was G6PD deficient. The mean oral artesunate dose per bodyweight was $11.8 \mathrm{mg} / \mathrm{kg}(\mathrm{SD} \pm 0.9)$, with no statistically significant difference demonstrated in the final total dose per bodyweight received between those in different dose-weight bands (Table 1 ).

At $48 \mathrm{~h}$ after treatment $44 / 49$ (90\%; CI 95 78-97) of patients were negative for parasites microscopically on blood smear. All patients were negative by $72 \mathrm{~h}$, and remained negative up to 28 days post-treatment (Table 3). The median parasite clearance time was $25.6 \mathrm{~h}$ (IQR 18.5-42), with the slowest clearance seen at the $72 \mathrm{~h}$ planned time-point in a patient with an initial parasite count at presentation of $44,622 / \mu \mathrm{L}$ (Fig. 2). In multivariable analysis including age, sex and artesunate dose per bodyweight, parasite count at presentation was the only independent predictor of parasite clearance time $(p=0.001)$.

Detailed parasite clearance estimation (using WWARN methodology [19]) could be derived on 45 (92\%) patients. Four patients were excluded as their parasite clearance was less than $12 \mathrm{~h}$ and insufficient for analysis. Of the 45 patients evaluated, the median time to $50 \%$ parasite

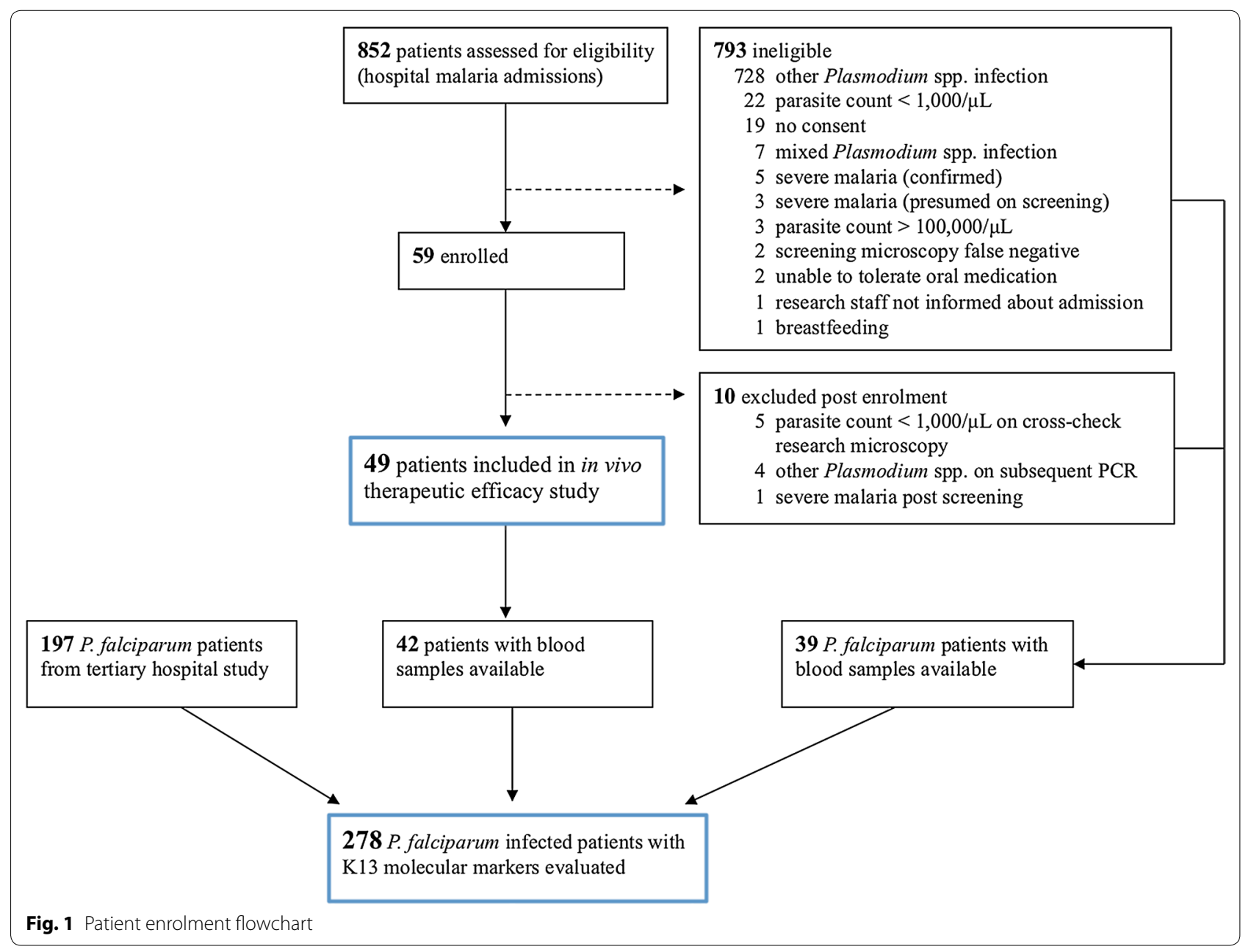


Table 2 Demographic and clinical data

\begin{tabular}{|c|c|}
\hline Patient characteristic & P. falciparum $(\mathrm{n}=49)$ \\
\hline \multicolumn{2}{|l|}{ Age, years } \\
\hline Median (IQR) & $18(11-31)$ \\
\hline Range & $3-62$ \\
\hline Children (age $\leq 12$ years), $\mathrm{n}$ (\% total) & $14(29)$ \\
\hline Male gender, $\mathrm{n}(\%)$ & $38(78)$ \\
\hline Previous malaria (self-reported), n (\%) & $7(14)$ \\
\hline History of chronic disease, n (\%) & $0(0)$ \\
\hline Days of fever, median (IQR) & $5(3-6)$ \\
\hline \multicolumn{2}{|l|}{ Symptoms on enrolment, $\mathrm{n}(\%)$} \\
\hline Rigors/chills & $33(67)$ \\
\hline Headache & $45(92)$ \\
\hline Vomiting & $24(49)$ \\
\hline Abdominal pain & $15(31)$ \\
\hline Diarrhoea & $6(12)$ \\
\hline Cough & $16(33)$ \\
\hline Shortness of breath & $5(10)$ \\
\hline Myalgia & $21(43)$ \\
\hline Arthralgia & $22(45)$ \\
\hline \multicolumn{2}{|l|}{ Examination findings on enrolment } \\
\hline Temperature, ${ }^{\circ} \mathrm{C}$, median (IQR) & $37.3(37.0-38.2)$ \\
\hline Fever, temp $\geq 37.5^{\circ} \mathrm{C}, \mathrm{n}(\%)$ & $20(41)$ \\
\hline Systolic blood pressure, mmHg, median (IQR) & $111(99-120)$ \\
\hline Heart rate, beats/min, median (IQR) & $96(83-106)$ \\
\hline Respiratory rate, breaths/min, median (IQR) & $22(20-24)$ \\
\hline Oxygen saturation, \%, median (IQR) & $99(98-100)$ \\
\hline Palpable liver, $n(\%)$ & $11(22)$ \\
\hline Palpable spleen, n (\%) & $5(10)$ \\
\hline \multicolumn{2}{|l|}{ Rash, n (\%) } \\
\hline \multicolumn{2}{|l|}{ Laboratory findings on enrolment } \\
\hline Parasite count, parasites/ $\mu \mathrm{L}$, median (IQR) & $9924(3466-24,276)$ \\
\hline Parasite count, parasites $/ \mu \mathrm{L}$, range & $1459-56,789$ \\
\hline $\begin{array}{l}\text { Parasite count, parasites } / \mu \mathrm{L} \text {, geometric mean } \\
\quad(95 \% \mathrm{Cl})\end{array}$ & $9463(6757-13,254)$ \\
\hline Ring proportion, mean \% (SD) & $89(0.24)$ \\
\hline Haemoglobin, g/dL, median (IQR) & $12.3(11.0-13.9)$ \\
\hline Anemia (baseline), n (\%)* & $24(49)$ \\
\hline G6PD deficiency present, n/N (\%) & $1 / 38(97)$ \\
\hline White blood cell count, $\times 10^{3} / \mu \mathrm{L}$, median (IQR) & $6.9(5.6-8.9)$ \\
\hline Neutrophil count, $\times 10^{3} / \mu \mathrm{L}$, median (IQR) & $4.1(2.5-6.0)$ \\
\hline Platelet count, $\times 10^{3} / \mu \mathrm{L}$, median (IQR) & $122(57-190)$ \\
\hline Thrombocytopenia (platelets $\left.<150 \times 10^{3} / \mu \mathrm{L}\right), \mathrm{n}(\%)$ & $30(61)$ \\
\hline Creatinine, $\mu \mathrm{mol} / \mathrm{L}$, median (IQR) & $69(50-82)$ \\
\hline Urea, mmol/L, median (IQR) & $4.6(3.3-5.8)$ \\
\hline Bilirubin, $\mu \mathrm{mol} / \mathrm{L}$, median (IQR) & $14.6(9.3-24.0)$ \\
\hline Glucose, mmol/L, median (IQR) & $6.3(5.5-7.1)$ \\
\hline Albumin, g/dL, median (IQR) & $34(28-37)$ \\
\hline
\end{tabular}

Table 2 (continued)

\begin{tabular}{ll}
\hline Patient characteristic & P. falciparum $(\mathbf{n}=\mathbf{4 9})$ \\
\hline ALT, IU/L, median (IQR) & $30(20-45)$ \\
Bicarbonate, mmol/L, median (IQR) & $20.9(20.0-22.8)$ \\
Acute kidney injury, n (\%) & $3(6)$ \\
Blood cultures positive, n (\%) & \\
\hline
\end{tabular}

* Anemia based on WHO 2011 haemoglobin measurement criteria [20]: age $6-59$ months $(\leq 100 \mathrm{~g} / \mathrm{dL}), 5-11$ years $(<115 \mathrm{~g} / \mathrm{dL}), 12-14$ years $(<120 \mathrm{~g} / \mathrm{dL})$, non-pregnant women $\geq 15$ years $(<120 \mathrm{~g} / \mathrm{dL})$, pregnant women $(<110 \mathrm{~g} / \mathrm{dL})$, men $\geq 15$ years $(<130 \mathrm{~g} / \mathrm{dL})$

${ }^{+}$Excluding results positive for skin contaminants

\section{Table 3 Parasitological response}

\begin{tabular}{|c|c|}
\hline Variable & Artesunate, $n=49$ \\
\hline \multicolumn{2}{|l|}{ Parasitological response } \\
\hline \multicolumn{2}{|l|}{$24 \mathrm{~h}$} \\
\hline Number negative & 29 \\
\hline$\%(\mathrm{Cl} 95)$ & $59.2(44.2-73.0)$ \\
\hline \multicolumn{2}{|l|}{$48 \mathrm{~h}$} \\
\hline$n$ & 44 \\
\hline$\%(\mathrm{Cl} 95)$ & $89.8(77.8-96.6)$ \\
\hline \multicolumn{2}{|l|}{$72 \mathrm{~h}$} \\
\hline $\mathrm{n}$ & 49 \\
\hline$\%(C \mid 95)$ & $100(92.7-100)$ \\
\hline \multicolumn{2}{|l|}{ Parasite clearance time (PCT) } \\
\hline Median hours & 25.6 \\
\hline (IQR)[range] & $(18.5-42)[7.9-73.9]$ \\
\hline \multicolumn{2}{|c|}{$\begin{array}{l}\text { Slope of curve }(k) \text { for } \log _{e} \\
\text { Normalised parasite clearance* }\end{array}$} \\
\hline Mean (k) constant (Cl 95) & $0.26(0.20-0.32)$ \\
\hline \multicolumn{2}{|l|}{ Slope of curve (k) half-life } \\
\hline Median hours (IQR) & $2.7(2.2-3.5)$ \\
\hline \multicolumn{2}{|c|}{ Slope of curve $(k)$ half-life $>5 \mathrm{~h}$} \\
\hline n (\%) & $3(6.7)$ \\
\hline \multicolumn{2}{|l|}{ Lag phase present } \\
\hline n (\%) & $9(20)$ \\
\hline \multicolumn{2}{|l|}{ Lag phase duration } \\
\hline Median hours (IQR) & $7.7(7.3-8.7)$ \\
\hline \multicolumn{2}{|l|}{$\mathrm{PCT}_{50}$} \\
\hline Median hours (IQR) & $4.3(2.0-8.4)$ \\
\hline \multicolumn{2}{|l|}{$\mathrm{PCT}_{90}$} \\
\hline Median hours (IQR) & $10.8(6.8-15.6)$ \\
\hline \multicolumn{2}{|l|}{$\mathrm{PCT}_{95}$} \\
\hline Median hours (IQR) & $13.4(9.0-18.6)$ \\
\hline \multicolumn{2}{|l|}{$\mathrm{PCT}_{99}$} \\
\hline Median hours (IQR) & $19.7(14.3-25.6)$ \\
\hline
\end{tabular}

* 45 (92\%) had data at $\geq 3$ time points allowing parasite clearance analysis 
clearance $\left(\mathrm{PCT}_{50}\right)$ was $4.3 \mathrm{~h}$ (IQR 1.9-8.4), and time to 99\% parasite clearance was $19.6 \mathrm{~h}$ (IQR 14.3-25.6). The mean slope of the $\log _{\mathrm{e}}$ normalised parasite clearance curve was 0.27 (95\% CI 0.24-0.30). The median half-life of the clearance slope was $2.7 \mathrm{~h}$ (IQR 2.2-3.5), with 3 (7\%) of patients having a clearance slope half-life greater than $5 \mathrm{~h}$. There was no difference in the median clearance slope half-life when comparing patients enrolled from each year during the study period.

\section{kelch13 molecular surveillance}

Molecular markers were conducted in 278 patients with falciparum malaria (Fig. 3), of whom 42 (86\%) had also been enrolled in the clinical efficacy study. All P. falciparum isolates were wild-type for the 21 kelch13 SNPs evaluated (GenBank Accession Numbers: MH721937-722214), including 98 (100\%) of those subsequently tested for the F446I polymorphism (unpublished). Cases were predominantly distributed from the West Coast administrative division of Sabah (158 [58\%]), followed by the northern Kudat division (111 [41\%]), with 5 (2\%) additional cases from the eastern Sandakan division (Fig. 3).

\section{Discussion}

Plasmodium falciparum parasites causing malaria in Sabah, Malaysia remain sensitive to treatment with oral artesunate, with no evidence of delayed in vivo parasite

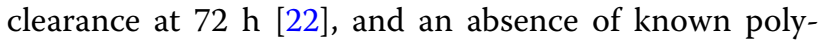
morphisms associated with artemisinin resistance in the kelch13 propeller domain [1]. No WHO criteria for suspected or confirmed endemic artemisinin resistance were present [23]. Confirmation of ongoing efficacy to the major component of ACT supports the continuation of standard WHO recommended ACT regimens as the first-line treatment for uncomplicated falciparum malaria in Malaysia [24], as is currently indicated in national malaria treatment guidelines [25]. ACT remains highly efficacious and the first-line treatment for the other endemic Plasmodium species causing malaria in Malaysia [25], which are commonly misidentified using microscopic diagnosis [26]. This includes uncomplicated human malaria due to zoonotic transmission of the monkey parasite Plasmodium knowlesi, for which ACT has faster parasite clearance, lower risk of anaemia and earlier hospital discharge compared to chloroquine [27, 28], and also malaria caused by Plasmodium vivax, for which high-grade chloroquine resistance has been demonstrated for blood-stage infections in Sabah [29].

Results from this study are consistent with another study from Sabah, which reported only wild-type kelch13 molecular markers using 17 SNPs from 50 P. falciparum isolates collected from 2008 to 2014 [30]. The absence of

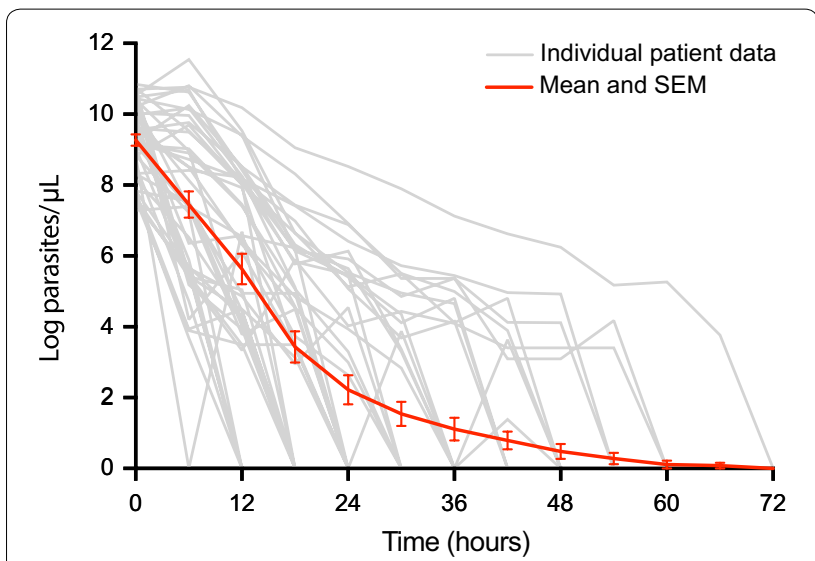

Fig. 2 Parasite clearance

P. falciparum artemisinin drug resistance in Malaysia, either spread from imported cases from neighbouring countries harbouring resistant $P$. falciparum parasites, or de novo resistance arising independently, is likely due in large part to the effective Malaysian malaria public health programme [25]. Malaysian Ministry of Health malaria guidelines stipulate all patients with confirmed malaria by microscopy require admission to hospital for free treatment and management, in addition to distribution of long-lasting insecticide-treated bed nets and active case detection for household contacts of reported cases in endemic areas $[3,25]$. ACT has been the first-line treatment for uncomplicated falciparum malaria since 2009, with centrally distributed artemether-lumefantrine (produced according to good manufacturing practice) preferentially used [25]. Widespread access to free supervised treatment has meant that counterfeit or poor quality artemisinin-based combinations, or partially completed courses of treatment, have not been a major concern, limiting the potential impact of these factors on the risk of independent resistance developing. Primaquine given as a single dose of $0.25 \mathrm{mg} / \mathrm{kg}$ for patients with normal G6PD activity for transmission blocking of gametocytes was also introduced in Malaysia in 2014, limiting the onward transmission risk and further drug exposure of parasites potentially developing artemisinin resistance.

Ongoing therapeutic efficacy monitoring for artemisinin derivatives should incorporate the use of kelch13 molecular markers, as these allow earlier detection of resistance compared to parasitological measures [1]. At the time of study design, and prior to the discovery of the kelch13 molecular markers, artemisinin resistance was best defined as the presence of delayed parasite clearance (microscopically positive for asexual $P$. falciparum at $72 \mathrm{~h}$ post-treatment with an ACT in those presenting with parasite counts $<100,000 / \mu \mathrm{L}$ ) in $\geq 3 \%$ of a treated 


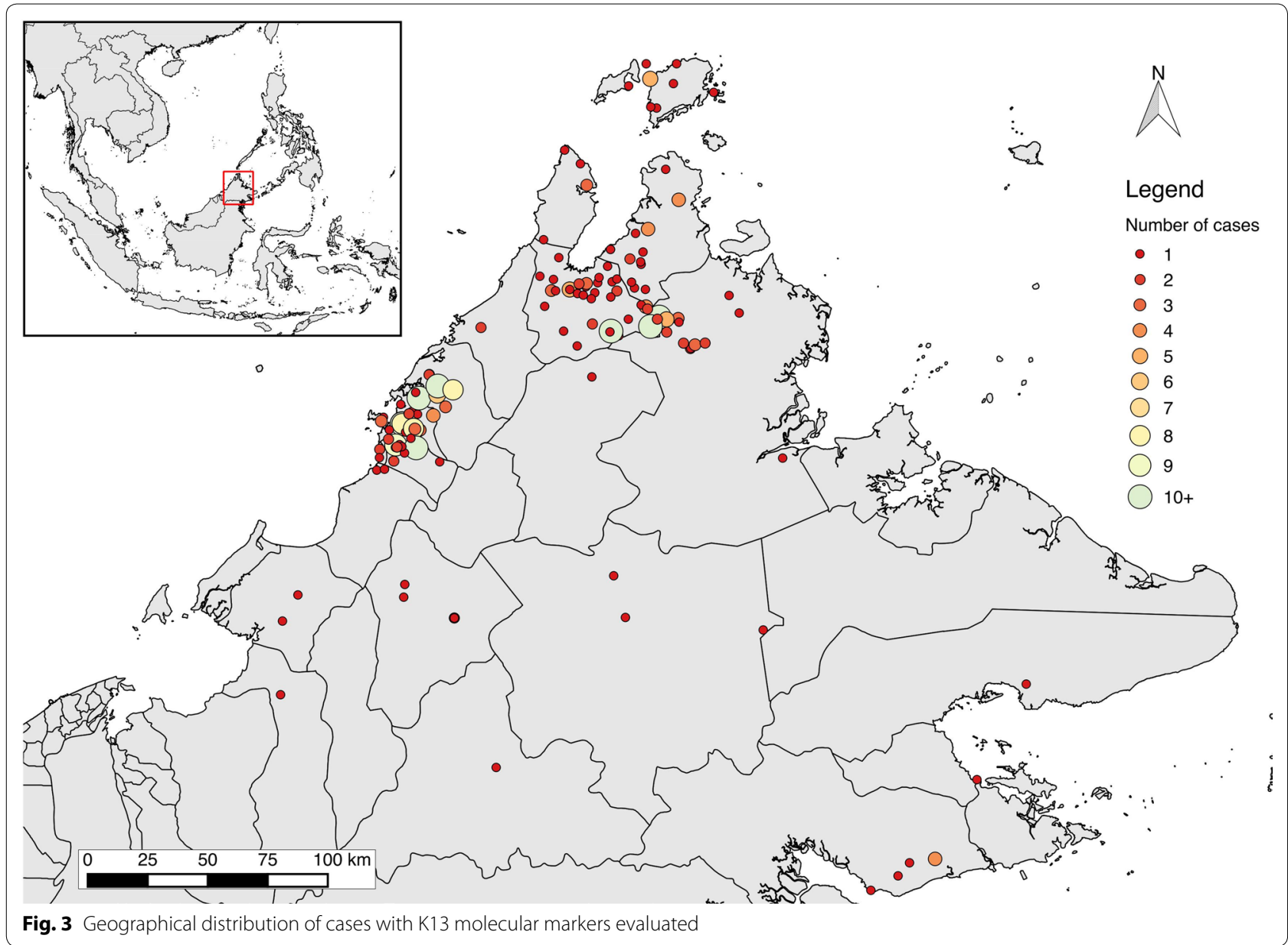

population [22]. However, this method has limitations as a regional strategy. Quantification of parasite clearance in countries using different artemisinin-based combination treatments are difficult to compare due to differences in the relative efficacy between the longer acting partner drugs. Initial efficacy of the ACT partner drug also masks the underlying development of early artemisinin resistance, leading to a higher risk of subsequent partner drug resistance $[7,8]$. Conventional methods of measuring parasite clearance also exclude the initial highly variable lag phase in the first $6-12 \mathrm{~h}$, which is impacted by the speed of action of the antimalarial and the life-cycle stage of parasites at the time of drug administration [31].

The ongoing decline in falciparum malaria cases in Sabah over the study period limited both the number of those able to be enrolled in the in vivo parasitological assessment, and also the overall number evaluated in the kelch13 molecular study component. Falciparum malaria cases able to have kelch13 marker surveillance conducted were predominantly from the western Sabah catchment area of the tertiary referral hospital in the state capital Kota Kinabalu. Although it is possible more remote interior areas were underrepresented, this area has both the highest population density and falciparum malaria transmission in Sabah, as well as significant numbers of official and unofficial migrants from surrounding falciparum-endemic countries.

Accurate evaluation of parasite clearance was possible by the study design utilising optimal dosing of oral artesunate $(4 \mathrm{mg} / \mathrm{kg})$ given in narrow weight bandings, with all patients receiving close to the target total dose of $12 \mathrm{mg} / \mathrm{kg}$. In contrast, the first-line ACT used in Malaysia, artemether-lumefantrine, has an effective artemisinin derivative component dose of $1.8 \mathrm{mg} / \mathrm{kg}$, given twice daily, with larger weight-bandings for standard WHOrecommended use known to result in lower efficacy among young children from Asia receiving $\leq 60 \mathrm{mg} / \mathrm{kg}$ total lumefantrine dose [32]. However, any potential differences in parasite clearance due to variation in dosing between the study design and standard ACT regimens in routine practice are not a result of underlying $P$. falciparum artemisinin resistance in this population given the absence of kelch13 polymorphisms. 


\section{Conclusion}

Plasmodium falciparum artemisinin resistance was not evident in Sabah, Malaysia from in vivo parasite clearance, or surveillance of kelch13 molecular markers. Current ACT regimens should continue to be used as the first-line blood-stage treatment for all Plasmodium species in Malaysia. With Malaysia approaching the elimination of falciparum malaria, ongoing molecular surveillance for artemisinin and partner drug resistance will be an important adjunctive tool in achieving and maintaining this goal. Wider surveillance for artemisinin and partner drug-resistant $P$. falciparum in other countries to the south and east of the Greater Mekong region will also be an important component in the success of their malaria elimination goals.

\section{Additional file}

Additional file 1. kelch13 molecular marker reference table.

\section{Authors' contributions}

TWY, TW, NMA and MJG conceived and designed the study. MJG, TW and GSR conducted the study with assistance from TWY, JJ, BEB, JM and NMA. KP and AA conducted the molecular laboratory work. MJG conducted the data analysis and wrote the first draft of the manuscript. All authors read and approved the final manuscript.

\section{Author details \\ ${ }^{1}$ Global and Tropical Health Division, Menzies School of Health Research and Charles Darwin University, Casuarina, PO Box 41096, Darwin, NT 0811 , Australia. ${ }^{2}$ Infectious Diseases Society Sabah-Menzies School of Health Research Clinical Research Unit, Kota Kinabalu, Sabah, Malaysia. ${ }^{3}$ Jesselton Medical Centre, Kota Kinabalu, Sabah, Malaysia. ${ }^{4}$ Clinical Research Centre, Queen Elizabeth Hospital, Ministry of Health, Kota Kinabalu, Sabah, Malaysia. ${ }^{5}$ QIMR Berghofer Medical Research Institute, Brisbane, QLD, Australia. ${ }^{6}$ Sabah Department of Health, Ministry of Health, Kota Kinabalu, Sabah, Malaysia. ${ }^{7}$ Vector Disease Sector, Disease Control Division, Ministry of Health, Kuala Lumpur, Malaysia. ${ }^{8}$ Centre for Tropical Medicine and Global Health, Nuffield Department of Clinical Medicine, University of Oxford, Oxford, UK. ${ }^{9}$ Lee Kong Chian School of Medicine, Nanyang Technological University, Singapore, Singapore. ${ }^{10}$ Communicable Disease Centre, Institute of Infectious Diseases and Epidemiology, Tan Tock Seng Hospital, Singapore, Singapore.}

\section{Acknowledgements}

We thank the study participants, the IDS-KKS malaria research team nursing and laboratory staff, and Malaysian Ministry of Health hospital directors and clinical staff at Kudat, Kota Marudu and Pitas District Hospitals. Thank-you to Christopher Wilkes for assisting with patient enrolments. We appreciate the valuable advice and resources provided by Elizabeth Ashley for study design and Sonia Goncalves and the Wellcome Sanger Institute for exclusion of F446I kelch mutations. We also recognise the support from Dr. Goh Pik Pin and the Clinical Research Centre, Queen Elizabeth Hospital, Kota Kinabalu, Sabah, and colleagues and staff of the UK Medical Research Council P. knowlesi Monkeybar Project. We would like to thank the Director General of Health Malaysia for permission to publish this article.

\section{Competing interests}

The authors declare that they have no competing interests.

\section{Availability of data}

K13 sequence data is freely available in GenBank (https://www.ncbi.nlm.nih. gov/genbank/; Accession Numbers: MH721937-722214).

\section{Ethics approval and consent to participate}

This study was approved by the Medical Research and Ethics Committee, Ministry of Health, Malaysia (NMRR-10-754-6684), and Menzies School of Health Research, Australia.

\section{Funding}

This study was funded by the Ministry of Health, Malaysia

(Grant \#BP00500420), the Australian National Health and Medical Research Council (Grants \#1037304 and \#1045156; fellowships to NMA [\#1042072], TWY [\#605831], BEB [\#1088738]; scholarship and fellowship to MJG [\#1074795 and \#1138860]; and 'Improving Health Outcomes in the Tropical North: A multidisciplinary collaboration 'Hot North', Grant \#1131932; fellowships MJG and $\mathrm{SA})$, and the Australian Centre of Research Excellence in Malaria Elimination. RNP is supported by a Wellcome Trust Senior Fellowship in Clinical Science (200909). TWY is funded by a Singapore National Medical Research Council Clinician Scientist Award (CSA INV 15nov007). The study was also supported by the Tropical Disease Research Regional Collaboration Initiative (TDRRCI), which is funded by the Australian Government and implemented by Menzies School of Health Research and the Burnet Institute. The views expressed in this publication are the author's alone and are not necessarily the views of the Australian Government.

\section{Publisher's Note}

Springer Nature remains neutral with regard to jurisdictional claims in published maps and institutional affiliations.

Received: 13 September 2018 Accepted: 23 November 2018 Published online: 10 December 2018

\section{References}

1. Ashley EA, Dhorda M, Fairhurst RM, Amaratunga C, Lim P, Suon S, et al. Spread of artemisinin resistance in Plasmodium falciparum malaria. N Engl J Med. 2014;371:411-23.

2. Imwong M, Suwannasin K, Kunasol C, Sutawong K, Mayxay M, Rekol H, et al. The spread of artemisinin-resistant Plasmodium falciparum in the Greater Mekong subregion: a molecular epidemiology observational study. Lancet Infect Dis. 2017;17:491-7.

3. WHO. World Malaria Report 2018. Geneva: World Health Organization; 2018. [Internet]. Available from: http://www.who.int/malaria/publicatio ns/world-malaria-report-2018/report/en/.

4. Ménard D, Khim N, Beghain J, Adegnika AA, Shafiul-Alam M, Amodu O, et al. A worldwide map of Plasmodium falciparum K13-propeller polymorphisms. N Engl J Med. 2016;374:2453-64.

5. Ariey F, Witkowski B, Amaratunga C, Beghain J, Langlois A-C, Khim N, et al. A molecular marker of artemisinin-resistant Plasmodium falciparum malaria. Nature. 2014;505:50-5.

6. Tun KM, Imwong M, Lwin KM, Win AA, Hlaing TM, Hlaing T, et al. Spread of artemisinin-resistant Plasmodium falciparum in Myanmar: a cross-sectional survey of the K13 molecular marker. Lancet Infect Dis. 2015;15:415-21.

7. Amaratunga C, Lim P, Suon S, Sreng S, Mao S, Sopha C, et al. Dihydroartemisinin-piperaquine resistance in Plasmodium falciparum malaria in Cambodia: a multisite prospective cohort study. Lancet Infect Dis. 2016;16:357-65.

8. Amato R, Lim P, Miotto O, Amaratunga C, Dek D, Pearson RD, et al. Genetic markers associated with dihydroartemisinin-piperaquine failure in Plasmodium falciparum malaria in Cambodia: a genotype-phenotype association study. Lancet Infect Dis. 2016;17:164-73.

9. White NJ. Can new treatment developments combat resistance in malaria? Expert Opin Pharmacother. 2016;17:1303-7.

10. William T, Jelip J, Menon J, Anderios F, Mohammad R, Awang Mohammad TA, et al. Changing epidemiology of malaria in Sabah, Malaysia: increasing incidence of Plasmodium knowlesi. Malar J. 2014;13:390.

11. Rajahram GS, Barber BE, William T, Grigg MJ, Menon J, Yeo TW, et al. Falling Plasmodium knowlesi malaria death rate among adults despite rising incidence, Sabah, Malaysia, 2010-2014. Emerg Infect Dis. 2016;22:41-8.

12. WHO. Severe malaria. Trop Med Int Health. 2014;19 Suppl 1:7-131. 
13. Padley D, Moody AH, Chiodini PL, Saldanha J. Use of a rapid, single-round, multiplex PCR to detect malarial parasites and identify the species present. Ann Trop Med Parasitol. 2003;97:131-7.

14. Imwong M, Tanomsing N, Pukrittayakamee S, Day NPJ, White NJ, Snounou G. Spurious amplification of a Plasmodium vivax small-subunit RNA gene by use of primers currently used to detect P. knowlesi. J Clin Microbiol. 2009;47:4173-5.

15. Worldwide Antimalarial Resistance Network WWARN, Menard D, Ariey F. PCR and sequencing for genotyping of candidate Plasmodium falciparum artemisinin resistance SNPs in the Kelch 13 gene [Internet]. Available from: http://www.wwarn.org/tools-resources/procedures/pcr-and-seque ncing-genotyping-candidate-plasmodium-falciparum-artemisinin.

16. Grigg MJ, William T, Barber BE, Rajahram GS, Menon J, Schimann E, et al. Age-related clinical spectrum of Plasmodium knowlesi malaria and predictors of severity. Clin Infect Dis. 2018;363:1017.

17. Barber BE, William T, Grigg MJ, Menon J, Auburn S, Marfurt J, et al. A prospective comparative study of knowlesi, falciparum, and vivax malaria in Sabah, Malaysia: high proportion with severe disease from Plasmodium knowlesi and Plasmodium vivax but no mortality with early referral and artesunate therapy. Clin Infect Dis. 2013:56:383-97.

18. WHO. Microscopy for the detection, identification and quantification of malaria parasites on stained thick and thin blood films in research settings. Geneva: World Health Organization; 2015. [Internet]. Available from: http://www.who.int/tdr/publications/microscopy_detec_ident_quantif/ en/.

19. Worldwide Antimalarial Resistance Network (WWARN). Methodology for the WWARN Parasite Clearance Estimator. [Internet]. 2015. Available from: http://www.wwarn.org/tools-resources/pce-methodology.

20. WHO. Haemoglobin concentrations for the diagnosis of anaemia and assessment of severity. Geneva: World Health Organization; 2011. [Internet]. Available from: http://www.who.int/vmnis/indicators/haemoglobi n.pdf.

21. Kidney Disease Outcomes Quality Working Group KDOQ. KDIGO clinical practice guidelines for acute kidney injury. Kidney Int Suppl. 2012;2:1-138.

22. Stepniewska K, Ashley E, Lee SJ, Anstey N, Barnes KI, Binh TQ, et al. In vivo parasitological measures of artemisinin susceptibility. J Infect Dis. 2010;201:570-9.
23. WHO. Artemisinin and artemisinin-based combination therapy resistance. Geneva: World Health Organization; 2017. [Internet]. Available from: http://apps.who.int/iris/bitstream/handle/10665/255213/WHO-HTMGMP-2017.9-eng.pdf? sequence $=1$.

24. WHO. Guidelines for the treatment of malaria. 3rd Edn. Geneva: World Health Organization; 2015.

25. Ministry of Health Malaysia VBDCP. Management Guidelines of Malaria in Malaysia [Internet]. Ministry of Health, Malaysia; 2013 Oct. Available from: http://www.moh.gov.my/index.php.

26. Barber BE, William T, Grigg MJ, Yeo TW, Anstey NM. Limitations of microscopy to differentiate Plasmodium species in a region co-endemic for Plasmodium falciparum, Plasmodium vivax and Plasmodium knowlesi. Malar J. 2013;12:8.

27. Grigg MJ, William T, Menon J, Dhanaraj P, Barber BE, Wilkes CS, et al. Artesunate-mefloquine versus chloroquine for treatment of uncomplicated Plasmodium knowlesi malaria in Malaysia (ACT KNOW): an openlabel, randomised controlled trial. Lancet Infect Dis. 2016;16:180-8.

28. Grigg MJ, William T, Barber BE, Rajahram GS, Menon J, Schimann E, et al. Artemether-lumefantrine versus chloroquine for the treatment of uncomplicated Plasmodium knowlesi malaria: an open-label randomized controlled trial CAN KNOW. Clin Infect Dis. 2018;66:229-36.

29. Grigg MJ, William T, Menon J, Barber BE, Wilkes CS, Rajahram GS, et al. Efficacy of artesunate-mefloquine for chloroquine-resistant Plasmodium vivax malaria in malaysia: an open-label, randomized, controlled trial. Clin Infect Dis. 2016;62:1403-11.

30. Norahmad NA, Razak MR, Abdullah NR, Sastu UR, Imwong M, Muniandy PK, et al. Prevalence of Plasmodium falciparum molecular markers of antimalarial drug resistance in a residual malaria focus area in Sabah, Malaysia. PLoS One. 2016;11:e0165515.

31. Khoury DS, Cromer D, Mohrle JJ, MCCarthy JS, Davenport MP. Defining the effectiveness of antimalarial chemotherapy: investigation of the lag in parasite clearance following drug administration. J Infect Dis. 2016;214:753-61.

32. Worldwide Antimalarial Resistance Network (WWARN). The effect of dose on the antimalarial efficacy of artemether-lumefantrine: a systematic review and pooled analysis of individual patient data. Lancet Infect Dis. 2015;15:692-702
Ready to submit your research? Choose BMC and benefit from:

- fast, convenient online submission

- thorough peer review by experienced researchers in your field

- rapid publication on acceptance

- support for research data, including large and complex data types

- gold Open Access which fosters wider collaboration and increased citations

- maximum visibility for your research: over $100 \mathrm{M}$ website views per year

At $\mathrm{BMC}$, research is always in progress.

Learn more biomedcentral.com/submissions 